\title{
Fragilidades experienciadas por crianças em internatos: reflexão bioética da obra Infâncias Perdidas
}

\section{Fragilities experienced by children in boarding schools: bioethical reflection of the work Lost Childhoods}

\section{Fragilidades experimentadas por niños en internados: reflexión bioética de la obra Infancias Perdidas}

\author{
Paloma dos Santos Trabaquini \\ Faculdades do Vale do Juruena (AJES)
}

Caroline Filla Rosaneli ${ }^{1}$

Thiago Rocha da Cunha

Pontifícia Universidade Católica do Paraná (PUCPR)

Cláudia Jaqueline Martinez Munhoz

Universidade Federal de Mato Grosso do Sul (UFMT)

\begin{abstract}
Resumo
O presente estudo tem o objetivo de realizar uma reflexão sobre a obra Infâncias Perdidas: $O$ Cotidiano nos Internatos-Prisão, de Sônia Altoé (2008), buscando evidenciar as fragilidades vivenciadas em contextos de internato nos anos 1980, no Brasil. O intuito desta reflexão, retrospectivamente trabalhada à luz da bioética, em que os recursos argumentativos tiveram como bases principais os princípios da Declaração Universal sobre Bioética e Direitos Humanos (DUBDH), é pautar a problemática da proteção da infância como um conflito permanente na sociedade brasileira. Trata-se de um estudo qualitativo, descritivo, utilizando a análise de conteúdo, a qual resultou na elaboração de categorias relativas às condições de vulneração e privação de liberdade; desrespeito à autonomia e à dignidade humana; discriminação e estigmatização social das crianças. A reflexão da obra evidencia as fragilidades históricas da infância, gerando uma perspectiva sobre responsabilidades éticas permanentes na proteção desses grupos mais vulneráveis da sociedade.

Palavras-chave: infância, direitos humanos, criança institucionalizada, bioética
\end{abstract}

\begin{abstract}
This study aims to reflect on the work Lost Infancy: The Daily Life in Boarding Schools-Prison (loosely translated), by Sônia Altoé (2008), seeking to highlight the weaknesses experienced in boarding school contexts in the 1980s in Brazil. The purpose of this reflection, retrospectively worked in the light of bioethics, in which the argumentative resources had as main bases the principles of the Universal Declaration on Bioethics and Human Rights (DUBDH), is to guide the issue of child protection as a permanent conflict in Brazilian society. It is a qualitative, descriptive study, using content analysis, which resulted in the elaboration of categories related to the conditions of vulnerability and deprivation of liberty; disrespect for autonomy and human dignity; discrimination and social stigmatization of children. The work's reflection highlights the historical weaknesses of childhood, generating a perspective on permanent ethical responsibilities in protecting these most vulnerable groups in society.

Keywords: childhood, human rights, institutionalized child, bioethics

Resumen

El presente estudio tiene el objetivo de realizar una reflexión sobre la obra Infancias Perdidas: el Cotidiano en los Internados-Prisión (traducción libre), de Sônia Altoé (2008), buscando evidenciar las fragilidades vivenciadas en contextos de internado en los años 1980, en Brasil. El objetivo de esta reflexión, retrospectivamente trabajada a la luz de la bioética, en que los recursos argumentativos tuvieron como bases principales los principios de la Declaración Universal sobre Bioética y Derechos Humanos (DUBDH), es pautar la problemática de la protección de la infancia como un conflicto permanente en la sociedad brasileña. Se trata de un estudio cualitativo, descriptivo, utilizando el
\end{abstract}

\footnotetext{
${ }^{1}$ Endereço para contato: Programa de Pós-Graduação em Bioética - Rua Imaculada Conceição, 1155, Prado Velho, Curitiba, Paraná. Telefone: (41) 99671-7930. E-mail: caroline.rosaneli@gmail.com
} 
análisis de contenido, la cual resultó en la elaboración de categorías relativas a las condiciones de vulneración y privación de libertad; irrespeto a la autonomía y la dignidad humana; discriminación y estigmatización social de los niños. La reflexión de la obra resalta las debilidades históricas de la infancia, generando una perspectiva sobre las responsabilidades éticas permanentes en la protección de estos grupos más vulnerables de la sociedad.

Palabras clave: infancia, derechos humanos, niño institucionalizado, bioética

\section{Introdução}

Uma condição de vulnerabilidade significativa como a vivida pela infância propaga a necessidade de dispensar uma importância especial a este estágio da vida, em particular quando esta se encontra aprisionada entre os muros de instituições.

À vista disso, é possível certificar a pertinência das pesquisas realizadas por Altoé (2008) no período de março de 1982 a abril de 1983, em sete estabelecimentos de internamento infantil, particularmente ao observar a posição que a infância ocupava na sociedade brasileira e, principalmente, relacionando-os a uma posição socioeconômica desfavorecida. Os internatos pesquisados pela autora compunham uma fundação filantrópica criada em 1936, localizada no estado do Rio de Janeiro, região sudeste do país, que prestava atendimento a crianças e adolescentes de zero a dezoito anos, oriundos de famílias carentes, crianças abandonadas e órfãs.

Somos apresentados aos internatos por intermédio da perspectiva da "prisão" das instituições totais, durante a leitura da obra Infâncias Perdidas: O Cotidiano nos Internatos-Prisão, resultante da tese de doutoramento de Sônia Altoé, obtida em 1988, pelo Departamento de Ciências e Educação da Universidade de Paris VIII.

Ao passo que cada capítulo prossegue, a autora nos apresenta aos principais acontecimentos relacionados à rotina dos internatos. Seu estudo detalhava o cotidiano dos indivíduos nestes internatos, retratando o caminho que os internos percorriam, desde a entrada, geralmente como recém-nascidos, até a maioridade, quando estes seriam desligados do sistema (Altoé, 2008). Identificaram-se algumas fragilidades no tratamento destes internos, tais como: sistema disciplinar rígido; submissão cega à autoridade; exclusão do meio familiar; situações de humilhação e violência; tratamento estigmatizante; necessidades básicas suprimidas; aprisionamento dentro das dependências do internato e sem muitas oportunidades de socialização com o meio externo.

Criada em 1964, por intermédio da Lei n. 4.513, de 1 o de dezembro de 1964, a Fundação Nacional do Bem-Estar do Menor (Funabem) "incorpora o patrimônio e as atribuições do Serviço de Assistência a Menores, e dá outras providências" (Brasil, 1964). Surgiu como uma grande instituição de assistência à criança e ao adolescente, sendo reportada a ela a responsabilidade pela internação de crianças carentes, abandonadas e infratoras. Teve também como finalidade a formulação e implementação da Política Nacional do Bem-Estar do Menor, por meio da elaboração de diretrizes políticas.

A referida lei foi revogada em 13 de julho de 1990, pela Lei de n. 8.069 (Brasil, 1990), que é marco legal vigente dos direitos especificamente voltados à criança e ao adolescente no Brasil. Conhecida como o Estatuto da Criança e do Adolescente (ECA), esta lei pronuncia-se sobre normas protetivas destinadas a indivíduos de zero a dezoito anos de idade, e se encontra vigente no atual ordenamento jurídico brasileiro. 
Neste contexto, como protetor maior do bem-estar da criança ou do adolescente, o Estado, no uso das prerrogativas determinadas pela Constituição, tem sob responsabilidade a criança e o adolescente cuja família não é a única provedora de cuidados.

Nas instâncias da lei, estabelecidas no art. 227, este tem o dever de prover educação, saúde e pleno desenvolvimento, cumprindo e fiscalizando, assim, todas as determinações legislativas próprias dessa camada social, tomando posse dos encargos de proteção integral e respeito aos direitos fundamentais do indivíduo (Constituição da República Federativa do Brasil [Brasil, 1988]).

Considerando que os conflitos éticos envolvendo a proteção da infância é um problema permanente nas diversas sociedades, o presente estudo tem como principal objetivo realizar uma reflexão sobre as fragilidades dos internos da fundação evidenciadas pela obra, sobre as condições vividas desde o nascimento até a maioridade, nos internatos de uma fundação filantrópica, conveniada à Fundação Nacional do Bem-Estar do Menor (Funabem), por intermédio da apreciação da obra Infâncias Perdidas: O Cotidiano nos Internatos-Prisão, de Altoé (2008).

\section{Método}

Trata-se de um estudo qualitativo descritivo, que busca refletir sobre a análise referenciada na obra de Altoé (2008), salientando bases importantes do contexto econômico, social, político e cultural das vulnerabilidades e fragilidades do ser humano, desde o início de sua vida.

Como pesquisa qualitativa descritiva, o trabalho se consistiu em categorias determinadas por amostra da população e fenômeno apresentados na obra Infâncias Perdidas, tendo como eixo orientador a compreensão de tais fenômenos voltados para a percepção dos direitos, intuição e subjetividade no contexto das relações humanas.

O estudo utiliza-se da análise de conteúdo segundo Bardin (2016), possibilitando a inferência de conhecimentos relativos às condições de produção e/ou recepção das mensagens e saberes pertinentes à temática, propondo um diálogo à luz da bioética.

As fragilidades apontadas na obra estudada foram distribuídas por temáticas determinadas a posteriori, de acordo com suas importâncias, a partir da leitura do livro e utilizando-se como marco comum a esse diálogo bioético e proposição normativa. O estudo assumiu como pressuposto referenciais da Declaração Universal sobre Bioética e Direitos Humanos (DUBDH) (Unesco, 2005), a partir dos quais os diversos interesses envolvidos condicionam-se inexoravelmente à garantia da dignidade e integridade da pessoa humana, para criação e discussão das categorias.

A reflexão foi assim distribuída em três categorias, com o intuito de facilitar o pensamento e introduzir o leitor na perspectiva da obra, além de propiciar a compreensão do panorama vivenciado na fundação.

\section{Resultados}

Os resultados são pautados a partir de três categorias elaboradas após leitura e reflexão da análise da obra referida, com base nos princípios fundamentais da DUBDH (Unesco, 2005), sendo estas ordenadas na seguinte configuração: 1 - Condições de vulneração, privação de 
liberdade e desrespeito à autonomia; 2 - Desrespeito à dignidade humana e integridade; 3 - Discriminação e estigmatização social.

\section{Condições de vulneração, privação de liberdade e desrespeito à autonomia}

Nesta categoria, tratou-se das vulnerabilidades em que se encontravam os sujeitos da obra estudada. Em todos os sete internatos, foi possível observar características que retratem atos de privação da liberdade, além de cada um apresentar típicas condições de vulneração de acordo com a faixa etária atendida.

A DUBDH destaca, em seu 8 o artigo, que o respeito à vulnerabilidade e à integridade pessoal expressa uma condição de obrigação, em que "indivíduos e grupos de vulnerabilidade específica devem ser protegidos e a integridade individual de cada um deve ser respeitada" (Unesco, 2005).

O referido respeito pela vulnerabilidade e integridade do indivíduo, bem como de grupos, como apontado no art. 8ㅇ, coloca em evidência que estes, estando em condições de vulneração, devem ser protegidos e respeitados. Deste modo, lança-se a vulnerabilidade para o centro de diversas discussões que permeiam os domínios da bioética, garantindo que a dignidade e os direitos humanos sejam preservados.

Conforme Neves (2006, p. 29), "Vulnerabilidade é uma palavra de origem latina, derivando de vulnus (eris), que significa ferida. Assim sendo, ela é irredutivelmente definida como susceptibilidade de ser ferido" (Neves, 2006). Susceptibilidade essa que podemos considerar elevada em se falando de crianças e adolescentes, principalmente aqueles em situação de internação.

Neste âmbito, um enquadramento faz-se necessário para a compreensão do assunto ao qual se insere a categoria em questão. Schramm evidencia a diferenciação conceitual dos termos vulnerabilidade e vulneração; e, por conseguinte, vulnerável e vulnerado, definidos em sua esfera de estudos, a Bioética da Proteção. Sendo assim, todos são susceptíveis à ferida, diferenciando-se em relação ao grau e à intensidade de tal susceptibilidade, podendo a vulnerabilidade, enquanto potencialidade à ferida, ser atribuída a qualquer ser vivo; e a vulneração, enquanto estado concreto, ser aquela em que a condição de ser "ferido" se consolida. Confere-se, então, a natureza de vulnerado àquele cuja ferida já ocorreu ou ainda ocorre (Schramm, 2006; 2008).

Manifesta-se, assim, a grande importância de agir em proteção a grupos e indivíduos que migraram da condição de vulneráveis e se inseriram no quadro de vulnerados, apresentando, desta maneira, a proteção como uma necessidade quando a situação de ameaça já foi lançada sobre o ser, de forma a indicar a existência real do dano, saindo, em consequência disto, do estado de susceptibilidade para o de vulnerado (Schramm, 2006; 2008; 2017).

Como forma clara de ilustrar tais condições de vulneração, é possível observar a impossibilidade de consentir acerca da internação, em que estas eram intermediadas pelo Juizado de Menores e pelos órgãos conveniados à Funabem, sem aceite algum desses indivíduos a serem institucionalizados (Altoé, 2008). Isso aumentava a evasão, fuga e a recusa em voltar à instituição das crianças maiores que saíam por um período de "férias", para as casas de suas famílias.

Dessa forma, esses indivíduos eram privados de um grande direito prescrito no art. 3으 da Declaração Universal dos Direitos Humanos (DUDH), no qual se afirma que "Todo ser 
humano tem direito à vida, à liberdade e à segurança pessoal" (Organização das Nações Unidas [ONU], 1948). "Se a liberdade é um modo de existir e não um ideal separado da existência, então a autonomia é sempre o exercício em que a liberdade se confronta com o seu contrário, com as determinações. Ela se exerce sempre num espaço ameaçado pela heteronomia" (Segre et al., 1998). A liberdade e seu direito a ela não podem ser vistos entre muros e opressão.

Os sentimentos de abandono e desproteção eram inegáveis, tanto pelo distanciamento familiar quanto pela própria vivência institucional. Não era dispensada uma atenção exclusiva a cada criança, visto o elevado número de crianças sob a responsabilidade de cada inspetor. Com o aprisionamento do próprio corpo e da expressão, não podiam ter nada em seu poder (objetos que lhe conferiam qualquer identidade), o que fazia por fortalecer estes sentimentos. Em circunstâncias gerais, as crianças eram abandonadas por sua própria sorte ao funcionamento desumano das instituições (Altoé, 2008).

Ao passo que começavam a se expressar, a fala era o suporte de comunicação e logo percebiam que não tinham voz, eram vedadas quaisquer manifestações de expressão e nada do que diziam era de alguma forma considerado pelos cuidadores:

A maior parte de seus atos e gestos são esvaziados de significação, até mesmo aqueles nos quais um suporte corporal é evidente, substituindo-a por uma significação alienante, inteiramente exterior à criança, a saber, a sequência, a disciplina (Altoé, 2008).

Era completamente desrespeitado o artigo 19 da DUDH, o qual considera que:

Todo o indivíduo tem direito à liberdade de opinião e de expressão, o que implica o direito de não ser inquietado pelas suas opiniões e o de procurar, receber e difundir, sem consideração de fronteiras, informações e ideias por qualquer meio de expressão (ONU, 1948).

Esta disciplina imposta aos menores era exigida de maneira desmedida para conter qualquer manifestação. O grande número de crianças por internato tornava imprescindível, segundo os responsáveis, o uso da disciplina como um aparelho de controle das crianças.

A rígida rotina estabelecida pelo internato se apresentava como uma necessidade para manter a ordem e o bom funcionamento institucionais, o que pode ser observado na seguinte fala de uma das diretoras do internato:

Não é tanto para que eles façam a sua necessidade, mas é mais uma questão de ensinar, dele aprender aonde deve ir e também de rotina. Porque ela (funcionária) tira, leva naquele determinado lugar, e lá dá banho e vai para a recreação ou para a cama, conforme o horário. É mais uma sequência, como você pode observar. Está no refeitório, do refeitório vai para o banheiro, do banheiro lava e vai para a cama ou vai brincar, conforme. A sequência é importante para manter um pouco de ordem, para haver condições de trabalho (Altoé, 2008).

Por intermédio deste relato, nota-se que tal ritual cotidiano não ia de acordo com as necessidades de cada criança, mas sim com a finalidade de dar seguimento à rotina e aos horários propostos. O controle sobre o corpo era total, as sensações corporais não eram respeitadas, não decidiam sobre si nem sobre suas necessidades biológicas (tais como ir ao banheiro, beber água e se alimentar), e os horários eram também estabelecidos para que tais necessidades fossem satisfeitas (Altoé, 2008). 
Apenas respeitar a autonomia do indivíduo não dá garantias de sua efetivação. Podemos afirmar que a autonomia não é um princípio ao qual todos os indivíduos possam usufruir, neste contexto, em que a autonomia é um ponto de referência para a discussão, faz-se necessário apresentar uma definição do que seria esse princípio:

Semanticamente, "autonomia" vem do grego autonomia, palavra formada pelo adjetivo pronominal autos _ que significa ao mesmo tempo "o mesmo", "ele mesmo" e "por si mesmo" _ e nomos _ que significa "compartilhamento", "lei do compartilhar", "instituição", "uso", "lei", "convenção". Nesse sentido, autonomia significa propriamente a competência humana em "dar-se suas próprias leis". Filosoficamente, "autonomia" indica a condição de uma pessoa ou de uma coletividade, capaz de determinar por ela mesma a lei à qual se submeter. Seu antônimo é "heteronomia" (Segre et al., 1998).

Em resumo, é possível constatar certa impossibilidade em manter um indivíduo autônomo em todas as fases de sua vida, da infância à velhice; em algum determinado momento, este não será portador de um mínimo necessário de autonomia sobre seus atos. Os sujeitos agem com autonomia quando podem deliberar sobre si mesmos, "[...] principalmente nos seus aspectos de auto-ordenação, auto-organização e autodeterminação" (Segre et al., 1998), sem a interferência de terceiros; ou seja, sendo inexistente a coação externa da pessoa, ela será autônoma.

O regime de internato não oferecia às crianças a oportunidade de desenvolver-se de maneira autônoma, ademais essa autonomia não Ihes era favorecida para seu avanço integral. Essas crianças de dois ou três anos (no processo de primeira transferência) não detêm a autonomia esperada para sua faixa de idade segundo os funcionários, o que gera uma maior dificuldade no tratamento delas (Altoé, 2008).

Então, como esperar que essas crianças tivessem um mínimo de autonomia perante as atividades diárias se esta não lhe era oferecida ou fora violada a todo momento desde sua entrada no internato, quando mais novas? A independência esperada dos menores se restringia à realização de tarefas cotidianas, tais como: alimentarem-se sozinhos, ir ao banheiro e trocar de roupa. Salvo estes, a autonomia só os era permitida quando uma ordem Ihe fosse concedida (Altoé, 2008). A criança, quando dependente do adulto para qualquer atividade a ser desempenhada dentro do internato, não foge ao controle institucional, estando à mercê de tudo que lhes era imposto.

O agir "por si mesmo", elucidando a liberdade de autorreger-se, deve ser prioridade diante de certos condicionamentos e determinismos impostos, conduzindo o homem à reflexão sobre que direção seguir/tomar.

[...] o princípio de autonomia vincula-se à relevância que o sujeito assume na modernidade, relevância esta inseparável da reivindicação da liberdade de pensamento, da hegemonia da razão frente aos dogmas religiosos e ao peso da tradição. O significado de autonomia passa então a ser compreendido não apenas como a tentativa de apreender racionalmente o mundo, mas também de dominá-lo e submetê-lo às finalidades humanas, por via do desempenho de uma razão subjetiva e independente (Segre et al., 1998).

Referenciando-se à DUBDH, em seu artigo 5o, "Deve ser respeitada a autonomia dos indivíduos para tomar decisões, quando possam ser responsáveis por essas decisões e respeitem 
a autonomia dos demais [...]", julgariam os cuidadores que os internos seriam totalmente desprovidos de tomar suas próprias decisões? Ou essa privação do direito à autonomia dos indivíduos era feita para gerar domínio? Indivíduos alienados tornam-se incapazes de ir contra o ordenamento de um sistema opressor. Este artigo prevê ainda que "Devem ser tomadas medidas especiais para proteger direitos e interesses dos indivíduos não capazes de exercer autonomia" (Altoé, 2008; Unesco, 2005).

Outro impedimento na elaboração de sua identidade própria era o descaso em manter irmãos juntos na mesma unidade; assim que saíssem do primeiro internato, já poderiam ser separados. O impedimento de permanecer junto ao seu único vínculo familiar sólido seria o ponto de partida para eliminar seu referencial de identidade. Não havia um cuidado em manter esse tipo de união, fato reconhecido pelos funcionários da instituição, que nada faziam para conservar tais relações, revelando certo desprezo aos sentimentos das crianças. Fatos recorrentes em estudos atuais da autora, que aponta a negação das recomendações desde 1990, do Estatuto da Criança e do Adolescente, de que irmãos permaneçam juntos (Altoé et al., 2011). As constantes transferências acarretavam também extravio das relações com os familiares que estariam fora do internato, uma vez que muitas transições não eram informadas, e, a partir do momento que os familiares iam visitá-los, os funcionários não detinham a informação da localização da criança (Altoé, 2008).

A família, indiferentemente do modo como é conceituada e caracterizada, é a base da sociedade, a primeira forma de socialização do indivíduo. A convivência familiar é condição relevante para a proteção, crescimento e desenvolvimento da criança e do adolescente, assim como são importantes, também, as transformações postas à família, em decorrência do sistema socioeconômico e político do capitalismo (Fante \& Cassab, 2007).

Enquanto permanecem na instituição, escorre por entre os dedos a possibilidade de uma infância digna a ser vivenciada, são inibidos de ser e se tornar criança, vivendo uma infância sem aconchego e proteção familiar (Fante \& Cassab, 2007).

Tais circunstâncias que privam a pessoa de ter uma vida objetivamente digna violam constantemente suas liberdades necessárias, as quais deveriam ser consolidadas como direitos básicos. Ao ser privado dessa liberdade, o indivíduo se dissocia da essência que o faz livre.

Conforme Sen (2010) expressa em diferentes momentos de sua obra:

Um número imenso de pessoas em todo o mundo é vítima de várias formas de privação de liberdade. [...] Essas privações restringem a vida social e a vida política, e devem ser consideradas repressivas mesmo sem acarretar outros males [...]; Como as liberdades políticas e civis são elementos constitutivos da liberdade humana, sua negação é, em si, uma deficiência (Sen, 2010).

Em análise mais atual sobre o papel do abrigo como instituição, Altoé et al. (2011) apontam que se cumpre uma função social importante no acolhimento, mas são mudanças que devem garantir um atendimento que considere cada criança na sua singularidade.

\section{Desrespeito à dignidade humana e integridade na perspectiva jurídica}

A "dignidade da pessoa humana" é prevista na Constituição Federal, em seu 10 artigo e inciso III, como um dos fundamentos que compõem o Estado Democrático de Direito, ine- 
rente à República Federativa do Brasil (Brasil, 1988). Tem o intuito, na importância de direito fundamental, de garantir ao cidadão o respeito a seus direitos perante a sociedade e o poder público, preservando o reconhecimento do valor do ser humano.

Apresentando-se a dignidade humana como um fundamento da República, é atribuída à categoria em estudo um valor absoluto, em que tal princípio serve como alicerce ao ordenamento jurídico vigente, tratando-se de um valor incontestável. Este princípio evidencia aquele que é fonte soberana do direito constitucional e detentor do maior valor que possa ser atribuído, o ser humano.

Portanto a promoção à dignidade humana apresenta-se em um grau anterior diante de sua proteção por intermédio da Constituição; para tanto, promover esse valor teria por finalidade cumprir os preceitos constitucionais de respeito à dignidade da pessoa humana diante da sociedade e de nosso sistema jurídico, viabilizando a reversão da condição de desonra ao princípio fundamental, tornando desnecessárias intervenções para sua efetivação.

Torna-se, então, um grande desafio conservar-se vivo e íntegro em uma sociedade que é amplamente influenciada por acentuados valores utilitaristas e capitalistas, além do acentuado individualismo que, por si só, gera um regime excludente aos interesses do sujeito em questão, negando o respeito à dignidade humana.

Nesta categoria, abordaremos as questões de desrespeito à dignidade humana e integridade, sendo reconhecidas tais condições em todos os internatos integrantes do estudo. Refere a autora, em sua obra: "O que perpassa todos os internatos indiferentemente é a disciplina, a mesmice, o determinismo, o massacre, o não reconhecimento, a vitória da morte psicológica" (Altoé, 2008). Isso fortalece o diálogo necessário a essa discussão referente a esta categoria.

A DUDH (ONU, 1948) traz em seu artigo 1ํ, especificamente, a questão voltada à dignidade, em que: "Todos os seres humanos nascem livres e iguais em dignidade e direitos. São dotados de razão e consciência e devem agir em relação uns aos outros com espírito de fraternidade". A dignidade humana, então, torna-se uma ferramenta que dá sentido e suporte para que se cumpram os direitos humanos, um valor fundamental. Esse artigo é reforçado na DUBDH, por intermédio do 2 o artigo, o qual reitera como um de seus objetivos: "[...] promover o respeito pela dignidade humana e proteger os direitos humanos, assegurando o respeito pela vida dos seres humanos e pelas liberdades fundamentais, de forma consistente com a legislação internacional de direitos humanos". Já no art. 3ํ da DUBDH, a dignidade humana se apresenta como um princípio que deve ser universalmente respeitado: "[...] A dignidade humana, os direitos humanos e as liberdades fundamentais devem ser respeitados em sua totalidade. Os interesses e o bem-estar do indivíduo devem ter prioridade sobre o interesse exclusivo da ciência ou da sociedade". Isso reforça novamente a importância que deve ser atribuída a esta condição tão própria do ser humano.

No que tange à criação da DUDH, em 1948, as condições vivenciadas pelas crianças já se apresentavam em desacordo com a declaração, visto que a pesquisa se deu nos anos de 1982 e 1983. Sendo um valor básico que fundamenta os direitos humanos, a dignidade da pessoa humana apresenta-se violada de forma constante, em todos os internatos.

A proteção à integridade humana toma grande importância em ambas as declarações voltadas ao respeito das condições e dos direitos próprios dos seres humanos. Em seu artigo $8^{\circ}$, a DUBDH aponta que "Os indivíduos e grupos particularmente vulneráveis devem ser 
protegidos, e deve ser respeitada a integridade pessoal dos indivíduos em causa" (UNESCO, 2005). E DUDH, em seu $5^{\circ}$ artigo, afirma que "Ninguém será submetido à tortura, nem a tratamento ou castigo cruel, desumano ou degradante" (ONU, 1948).

Podemos observar essas condições de desrespeito à dignidade humana e integridade com grande intensidade nos internatos 1 e 2 , onde é natural que as crianças pequenas comecem a desenvolver seu senso de autonomia e cuidados sobre o próprio corpo. Ao mostrar-se como sujeito, demonstrando qualquer expressão de liberdade ou autonomia, este era castigado.

A partir do momento que entrasse no internato, a criança era vista como um número, "uma criança-objeto", o que de antemão a caracterizava como indigna de construir sua identidade, colocando-a imediatamente na condição de ser extremamente vulnerável. "A criança não é sujeito em nenhum momento" (Altoé, 2008).

A recusa em permitir que estes pudessem desenvolver suas noções de identidade, ou o impedimento da própria expressão, acabava por gerar uma condição de vulneração ainda maior nesses indivíduos, visto que:

A "identidade" só nos é revelada como algo a ser inventado, e não descoberto; como alvo de um esforço, "um objetivo"; como uma coisa que ainda se precisa construir a partir do zero ou escolher entre alternativas e então lutar por ela e protegê-la lutando ainda mais - mesmo que, para que essa luta seja vitoriosa, a verdade sobre a condição precária e eternamente inconclusa da identidade deva ser, e tenda a ser, suprimida e laboriosamente oculta (Bauman, 2005).

Impedidos de se manifestar, tanto de forma explícita quanto da maneira mais sutil possível, o menosprezo pela formação de identidade deles era evidente. Sem estímulos para seu desenvolvimento e construção de sua identidade pessoal, o que restava a eles era aceitar sua condição de alienação, imposta por uma organização totalmente despreparada para a formação de indivíduos independentes.

A instituição considerava a necessidade de obediência cega à autoridade, impondo, assim, disciplina com muita severidade, provocando situações de constrangimento, castigo, humilhação, e ainda violência física e sexual. Situações estas, em discordância com a DUDH, art. 50, em que "Ninguém será submetido à tortura nem a tratamento ou castigo cruel, desumano ou degradante" (Altoé, 2008; ONU, 1948).

A condição de vulneração humana perpassa inúmeros dilemas morais, em que limites são impostos a grupos considerados vulnerados. Os menores são privados de adotar uma identidade própria, o que gera a incapacidade de exercer sua autonomia. Incorporar a identidade como um suporte da autonomia é conceder ao indivíduo individualidade e personalidade, manifestando a importância de autoconhecer-se para se tornar um ser digno. A proteção é especialmente voltada a estes vulnerados, vítimas de circunstâncias desfavoráveis ao seu desenvolvimento, provenientes do desamparo das instituições que não prestam suporte básico para reduzir o nível de vulnerabilidade em que se encontram. "Em suma, proteger significa dar as condições de vida que cada qual julgue necessárias para capacitá-lo na tomada de suas próprias decisões enquanto ser racional e razoável" (Schramm, 2008). 


\section{Discriminação e estigmatização social}

Vários são os pontos em que discriminação e estigmatização são apresentados por Altoé (2008). Nesta categoria, ao relacionar estes temas com os apontamentos feitos pela autora, faz-se importante manifestar sua relevância como meio de debate da bioética.

Nenhuma pessoa deveria sofrer por discriminação ou estigmatização, seja qual for a motivação, principalmente por ir em oposição aos direitos e à dignidade humana. O jovem por si só se sentia discriminado por ter sido deixado no internato e não poder retornar para sua casa. Internados, muitas vezes, contra sua vontade, por falta de condições financeiras da família, isso os impedem de manter um convívio com o meio externo ao internato (Altoé, 2008), o que gera uma fragilidade muito maior às demandas discriminatórias.

Para a DUBDH, as questões voltadas à não discriminação e não estigmatização estão destacadas em seu artigo 11, evidenciando a relevância desse recorte para a presente discussão: "Nenhum indivíduo ou grupo deve ser discriminado ou estigmatizado por qualquer razão, o que constitui violação à dignidade humana, aos direitos humanos e liberdades fundamentais" (Unesco, 2005). Tal violação à dignidade humana e aos direitos seria o agente fomentador do estigma e da discriminação, já que estes "[...] constituem violações à dignidade humana, remete à concepção de que estigma e dignidade humana estão intrinsecamente associados; um só existe na negação do outro" (Godoi \& Garrafa, 2014).

Uma parcela do estigma iniciava quando a criança entrava em idade escolar, e os próprios professores, funcionários conveniados do estado ou município que prestam serviços à Fundação, julgavam esse indivíduo como "[...] pobre, perigoso, desinteressado, ruim, tem pouca inteligência, não aproveita aquilo que o internato lhe dá de bom grado, nem a oportunidade de estudar e melhorar de vida", simplesmente por serem alunos advindos dos internatos. O próprio sistema fomentava o estigma, criando artifícios para corroborar que o interno não se desenvolvia por "[...] falta de inteligência, capacidade, atenção e interesse" (Altoé, 2008). Muitos percebiam tal preconceito proveniente dos professores, fazendo com que alguns perdessem o interesse em participar das aulas, gerando significativos atrasos escolares.

Comportamentos divergentes à disciplina imposta na instituição eram tidos apenas como desvio próprio do indivíduo, e não consequentes de uma estrutura física e organizacional, falhas. Desta forma, as dificuldades de aprendizagem apontadas, e algumas práticas violentas dos jovens, acabavam por ganhar um rótulo que passa a representar determinado aluno para o restante de seu tempo no internato. Julgar ser individual a fonte dos problemas confrontados nos internatos proporciona à instituição a responsabilidade de restaurar o jovem que só poderia ser feita por esta, tendo em vista que o menor, desde sempre, esteve no internato. Assim, o ideal do trabalho "oferece" uma alternativa capaz de nortear os jovens, impondo a disciplina como forma de contribuir para o cumprimento de regras e normas sociais (Altoé, 2008).

O sentimento de desvalorização e discriminação estava sempre presente, quando todos seus atos eram julgados passíveis de receber castigos; quando havia diferenciação no alimento que lhes era servido (funcionários não faziam suas refeições junto dos internos; alimento servido se diferenciava do oferecido aos alunos; usavam pratos e talheres e podiam repetir); e sofriam humilhações constantes dos servidores do internato (Altoé, 2008). 
Estes grupos apresentavam grandes desvantagens, a estigmatização e discriminação sofrida eram evidenciadas nos processos de saída da instituição de internamento, em que muitos desses jovens ainda não tinham certidão de nascimento ou qualquer outro documento que os tornassem cidadãos perante a sociedade. O peso da discriminação se tornava mais expressivo ao sair dos muros institucionais e adentar a sociedade externa, uma sociedade que não os via como membros, dificultando sua entrada no mercado de trabalho e convívio em geral. Assim, muitos encaminhavam-se para a "vida do crime", tal como o estigma imposto sobre estes já havia previsto (Altoé, 2008).

Goffman (1980), ao definir o estigma como "uma categoria ou um atributo" fortemente depreciativo ao homem, deste modo, inferiorizando seu portador e o colocando em um nível menor que outrem, evidencia que essa inferiorização do ser contradiz ao que almejamos por dignidade humana, desumanizando a pessoa estigmatizada. O estigma toma conta de sua identidade e passa a definir o próprio ser, e este passar a ser conceituado pelo estigma que carrega, inviabilizando o reconhecimento de outras qualidades formadoras deste indivíduo. "Um estigma, é então, um tipo especial de relação entre atributo e estereótipo, embora eu proponha a modificação desse conceito, em parte porque há importantes atributos que em quase toda a nossa sociedade levam ao descrédito".

As fragilidades apresentadas remetem à privação da dignidade, depreciando o indivíduo, dando o sentido de ser menor que outro ser humano, não detendo os seus direitos, isento de deliberar sobre sua própria vida. A estigmatização, nestes casos, torna-se origem de sofrimento e "invisibilidade social". Essa atenuação do ser diante da sociedade ocorre como meio de buscar formas para adequar-se aos padrões, a fim de alcançar seu reconhecimento como cidadão (Godoi \& Garrafa, 2014).

\section{Discussão}

A obra posta em reflexão, por intermédio deste artigo, permite-nos atravessar o limite de pensamento e reconhecer verdadeiramente a realidade que muitos de nossos jovens vivenciavam, uma totalmente diferente do que era conhecido. A separação dos capítulos realizada pela autora nos insere de tal forma em sua experiência, que, por um momento, é possível partilhar o seu sentimento de indignação ao tratamento disponibilizado àquelas crianças. $A$ importância desta obra histórica vai além de uma simples investigação sobre os internatos, mas busca evidenciar a frágil condição à qual vidas humanas eram submetidas.

Ainda é de certa pertinência retornar àquele contexto, pois o viés histórico acaba por não ser benéfico às crianças e aos adolescentes. A infância era e ainda é desvalorizada pelas ações impiedosas da humanidade, que se esquece dos direitos do indivíduo, efetivando práticas de abandono e morte de certas populações, perpetuadas até o momento atual.

Fazendo o uso da bioética nesta reflexão, é possível perceber que os problemas ainda persistem, é o velho cenário com dados atualizados. Uma coincidência de tempos. Apesar de mudanças legais e institucionais terem surgido, a essência do sofrimento e do abandono ainda se faz presente. A bioética apresenta-se, nesse contexto, como auxílio na busca do reconhecimento e representatividade desses indivíduos como sendo, também, portadores de dignidade, a fim de conferir uma dimensão mais humana e dispor de uma maior atenção a este grupo em estudo. Chama atenção, em especial a este grupo de ins- 
titucionalizados, fadado ao esquecimento por não ser primordial a um funcionamento social padrão.

Portanto realizar esta reflexão é reconhecer a obra como um marco dos estudos sociais, a qual testemunha a grande dificuldade em ser criança e adolescente, em especial para aqueles dotados de condições socioeconômicas, políticas e culturais desfavoráveis em nosso país, pois é da nossa realidade passada a que se refere.

A obra é memória de um passado recente e ainda vigente, em que o Estado negligencia sua responsabilidade pela promoção e proteção de direitos de crianças e adolescentes. À vista disso, a observância em relação à Proposta de Emenda à Constituição (PEC) 33/2012, ainda aguardando votação pela Comissão de Constituição, Justiça e Cidadania do Senado, que reduz a maioridade penal para dezesseis anos (Proposta de Emenda à Constituição 33/2012 [Brasil, 2012]). Em meio a uma sociedade discriminada e estigmatizada, reduzir a maioridade penal afetará, principalmente, jovens pobres e de periferia; ou seja, tal emenda não abraçaria toda uma comunidade, não resolvendo, assim, o problema da violência que buscam sanar com tal proposta. Desta forma, fomenta-se a segregação já existente relacionada a determinadas classes desde a juventude, de forma a criminalizar a adolescência pobre, privando-a de quaisquer perspectivas de mudanças sociais, tornando-a alvo do excludente e opressor Estado.

Altoé et al. (2011) apontam que se faz necessária a construção de uma narrativa sobre a própria história dos internos, a fim de possibilitar ao sujeito contar-se de um modo diferente, permitindo à criança e ao adolescente seguir a vida com as possibilidades.

Segundo um apontamento realizado pelo Cadastro Nacional de Crianças e Adolescentes Acolhidos (CNCA), elaborado pelo Conselho Nacional de Justiça (CNJ) para fiscalizar políticas de acolhimento à infância e juventude, em fevereiro de 2018, o Brasil contava com 47.445 crianças e adolescentes residindo em 4.267 abrigos ou estabelecimentos sustentados por organizações não governamentais e distribuídos pelo país, estabelecimentos estes que se blindam contra qualquer aspecto externo a eles (Conselho Nacional de Justiça, 2018; Coimbra, 2014).

Diversas justificativas de mudanças e melhorias já foram propostas e implementadas, mas, em vista do montante de crianças que ainda permanecem em abrigos, alegar que todas foram acatadas e fazem alguma diferença na atual situação é um caminho incerto.

Como fruto do início de tais mudanças no que diz respeito ao direito de crianças e adolescentes, o ECA "[...] dispõe sobre a proteção integral à criança e ao adolescente" e define "[...] criança, para os efeitos desta Lei, a pessoa até doze anos de idade incompletos, e adolescente aquela entre doze e dezoito anos de idade", que "[...] gozam de todos os direitos fundamentais inerentes à pessoa humana, sem prejuízo da proteção integral" (Brasil, 1990). Esses direitos são referentes a toda criança e adolescente, sem tipo algum de discriminação e voltados ao melhor interesse destes, além de atribuir e promover valor a esta categoria humana, antes vista em qualidade inferior diante do corpo social e do direito brasileiro.

A alteração legal mais recente, data de 22 de novembro de 2017, a qual dispõe sobre a nova Lei de Adoção, Lei n. 13.509/2017, que reduz o período de permanência nos programas de acolhimento para 18 meses, a fim de acelerar os processos de adoção e reduzir a permanência institucional, buscando um bem-estar para as crianças de maneira mais ágil, entre outras mudanças (Brasil, 2017). Ademais, a realidade judicial acaba por, muitas vezes, 
não conseguir cumprir a lei; posto isso, a grande demora observada nos processos adotivos aumenta o período de acolhimento institucional a que as crianças à espera são submetidas.

Será que tais mudanças são realmente suficientes? Tal pergunta não pretende insinuar total descaso do Estado em relação a crianças e adolescentes, mas lançar a certeza de que não devemos nos enganar com a adição de tais garantias à legislação maior, se estas não forem verdadeiramente cumpridas em ordem do Estado, pois existe ainda, historicamente, um padrão de intolerantes, que vestem a sociedade de uma ideologia excludente. A resposta da questão anterior é muito simples. O que se faz realmente necessário é destinar nossas atenções ao passado, a fim de que toda a condição, antes vivenciada por nossas crianças, não seja repetida nos tempos posteriores.

A própria sociedade aprisiona a infância quando não abre mão de saber em que condições esta se encontra (Lourau, 2008). Principalmente quando aprisiona em instituições com dimensões funcionais e estruturais muito próximas às instituições totais, que são apresentadas por Goffman (1974) em sua publicação Manicômios, prisões e conventos. Instituições estas que separam esses indivíduos da sociedade por um longo período, em que são impostos a uma vida fechada e com uma rigorosa administração, resultando em grandes consequências em sua formação.

Obras como a de Goffman (1974) e Altoé (2008) são de extrema relevância para os tempos atuais, pois nos mostram como funcionavam as instituições totais e como estas muito se assemelhavam com as consequências geradas a seus internos. Essas duas esferas muito se aproximam quanto às suas exigências, destacando-se a disciplina rígida e as rotinas diárias impostas, a submissão à autoridade, além da anulação da pessoa como sujeito.

O indivíduo internado sofre uma espécie de "mortificação do eu", como descrito por Goffman (1974) em vários momentos de sua obra. A pessoa separada do mundo externo acaba por deixar escapar os sentidos que a fazem humana, o seu "eu" se esvai, perdendo a significação de segurança pessoal e controle sob seu próprio corpo e necessidades. Nas instituições, todas as suas concepções humanas são violadas, o seu ser é invadido.

A infância é, sem dúvidas, uma fase de grande relevância para a construção do indivíduo como sujeito. Todo o tempo passado dentro dos internatos foi um tempo irrecuperável mediante a ausência de uma formação segura como ser humano, furtando-se deste indivíduo a presença afetiva, educacional e social que poderia ter recebido caso se encontrasse em uma situação diferente de vida.

Ao ser tratada como objeto, toda e qualquer relação de afeto se extingue, já que objetos não necessitam de demonstrações de carinho e afeição, impedindo, assim, o desenvolvimento de sua identidade. Como forma de reduzir ainda mais essas possibilidades de desenvolvimento, o desrespeito às necessidades básicas do indivíduo, com disciplina rígida e alienante, e, principalmente, a exclusão do meio externo e do convívio familiar fazem da experiência de vida marcas demasiadas.

Essas crianças que estavam abrigadas, além de serem vulneráveis como todas as outras, foram vulneradas devido a todas as condições vivenciadas dentro do internato. Os valores institucionais se inocularam de tal forma em suas cabeças, de modo a esmagar sua identidade, mais precisamente na busca de seus valores e dessa identidade não apenas perdida, mas incapacitada de se criar. 
Retornar à sociedade, advindo de instituições totais, é um fator que acaba por gerar rótulo a indivíduos de maneira geral. Mas o impacto é muito maior em se tratando de crianças, o que é confirmado pela incapacidade destas de viver em uma sociedade complexa, à vista de uma formação totalmente falha. Uma formação que não os permitia a autonomia sobre si próprios e a criação de sua identidade pessoal, promovendo segregação e separação social, reduzindo o sujeito pura e simplesmente a um rótulo estigmatizante.

\section{Conclusão}

A reflexão da obra nos lança a importantes considerações sobre as inúmeras fragilidades evidenciadas no relato da autora sobre a dolorosa desumanização iniciada em seres humanos de forma prematura, em indivíduos em situação de internação. Tantas crianças e adolescentes que passaram e passam por fundações e internatos são privados do bem mais precioso da vida, que é a dignidade de ser humano. Apesar dos avanços do ordenamento jurídico brasileiro em defesa da infância e juventude, das intervenções dos órgãos competentes, assim como das políticas públicas, considera-se que ainda não há efetiva proteção dos vulneráveis.

A bioética se insere nessa discussão como intermediadora, na busca de soluções dos conflitos existentes, priorizando e possibilitando o auxílio aos vulnerados, os quais não detêm um conhecimento do processual acerca da conduta necessária para adotar uma postura que os capacitem a deliberar sobre suas vidas.

A DUBDH apresentou-se essencial para a construção do presente estudo, contribuindo com seus princípios para a elaboração das categorias em discussão e fornecendo subsídios para as argumentações necessárias ante o tema proposto.

Adentrar as dependências institucionais como um ser humano puro e, ao deixá-las, estar preenchido por condutas transgressoras, tornando-se irreconhecível como cidadão digno de pertencer a uma sociedade "padrão", não justifica a necessidade de manter esses indivíduos aprisionados, a fim de modificá-los e privá-los totalmente de seu pleno desenvolvimento como seres humanos que são. Excluso de estratégias que facilitassem sua reinserção na comunidade, ao deixar a entidade de abrigamento, o indivíduo se sente incapaz de pertencer àquele meio, já que sua existência sempre foi resumida a sofrimentos, transformando-se num indivíduo anulado e sem identidade própria.

Esse sistema falho na proteção dos direitos das crianças e dos adolescentes acaba por colocar estes seres, que, por inúmeras razões, já são vulneráveis, em uma condição de vulneração ainda maior. Excluídos do convívio familiar e social, transformam suas vidas em um cotidiano de submissão e ócio, de forma que são anulados como sujeitos e têm o desenvolvimento como pessoa impedido. Portanto resolver essas questões significaria o pleno respeito aos direitos desses indivíduos.

Não seria, então, toda essa condição vivenciada dentro e fora dos muros institucionais uma forma de abuso e violência de mais alto grau cometida contra o ser humano?

\section{Referências}

Altoé, S. (2008). Infância perdida: O cotidiano nos internatos-prisão. Rio de Janeiro: Centro Edelstein de Pesquisas Sociais. Recuperado de https://static.scielo.org/scielobooks/69ysj/ pdf/altoe-9788599662946.pdf 
Altoé, S., Silva, M., \& Pinheiro, B. S. (2011). A inconstância dos laços afetivos na vida das crianças e adolescentes abrigados. Revista Psicologia Política, 11(21), 109-122.

Bardin, L. (2016). Análise de conteúdo. São Paulo: Edições 70.

Bauman, Z. (2005). Identidade: Entrevista a Benedetto Vecchi. Rio de Janeiro: Zahar.

Brasil. (1964). Lei n. 4.513, de 10 de dezembro de 1964. Autoriza o Poder Executivo a criar a Fundação Nacional do Bem-Estar do Menor, a ela incorporando o patrimônio e as atribuições do Serviço de Assistência a Menores, e dá outras providências. Brasília, DF. Recuperado de http://www2.camara.leg.br/legin/fed/lei/1960-1969/lei-4513-1dezembro-1964-377645-publicacaooriginal-1-pl.html. Acesso: 13 Abr. 2018.

Brasil. (1988). Constituição da República Federativa do Brasil. Brasília-DF. Recuperado de http://www2.camara.leg.br/legin/fed/consti/1988/constituicao-1988-5-outubro-1988322142-publicacaooriginal-1-pl.html

Brasil. (1990). Lei n. 8.069, de 13 de julho de 1990. Dispõe sobre o Estatuto da Criança e do Adolescente e dá outras providências. Brasília, DF. Recuperado de: http://www. planalto. gov.br/ccivil_03/LEIS/L8069.htm. Acesso: 13 Abr. 2018.

Brasil. (2012). Proposta de Emenda à Constituição 33/2012. Altera a redação dos arts. 129 e 228 da Constituição Federal, acrescentando um parágrafo único para prever a possibilidade de desconsideração da inimputabilidade penal de maiores de dezesseis anos e menores de dezoito anos por lei complementar. Brasília, DF. Recuperado de https://www25.senado. leg.br/web/atividade/materias/-/materia/106330

Brasil. (2017). Lei n. 13.509, de 22 de novembro de 2017. Dispõe sobre adoção e altera a Lei n. 8.069, de 13 de julho de 1990 (Estatuto da Criança e do Adolescente), a Consolidação das Leis do Trabalho (CLT), aprovada pelo Decreto-Lei n. 5.452, de 1 o de maio de 1943, e a Lei n. 10.406, de 10 de janeiro de 2002 (Código Civil). Brasília, DF. Recuperado de http:// www.planalto.gov.br/ccivil_03/_ato2015-2018/2017/lei/L13509.htm

Coimbra, J. C. (2014). "Infâncias perdidas" de ontem e de hoje: A atualidade de uma pesquisa. Revista Psicologia Política, 14(31), 625-629.

Conselho Nacional de Justiça. (2018). Cadastro Nacional da Criança Acolhida. CNJ. Recuperado de http://www.cnj.jus.br/cnca/publico/

Fante, A. P., \& Cassab, L. A. (2007). Convivência familiar: Um direito à criança e ao adolescente institucionalizado. Textos \& Contextos, 6(1), 154-174.

Godoi, A. M. M., \& Garrafa, V. (2014). Leitura de bioética do princípio da não discriminação e não estigmatização. Saúde e Sociedade, 23(1), 157-166.

Goffman, E. (1974). Manicômios, prisões e conventos. São Paulo: Perspectiva.

Goffman, E. (1980). Estigma: Notas sobre a manipulação da identidade deteriorada. Rio de Janeiro: Zahar.

Lourau, R. Prefácio. In Altoé, S. (2008), Infância perdida: O cotidiano nos internatos-prisão. Rio de Janeiro: Centro Edelstein de Pesquisas Sociais.

Neves, M. C. P. (2006). Sentidos da vulnerabilidade: Característica, condição, princípio. Revista Brasileira de Bioética, 2(2), 157-72.

Organização das Nações Unidas para a Educação, a Ciência e a Cultura. (2005). Declaração Universal sobre Bioética e Direitos Humanos. Brasília: Cátedra Unesco de Ética da Universidade de Brasília/Sociedade Brasileira de Bioética (SBB). 
Organização das Nações Unidas. (1948). Declaração Universal dos Direitos Humanos. Genebra: ONU. Recuperado de http://www.ohchr.org/EN/UDHR/Documents/UDHR_ Translations/por.pdf

Schramm, F. R. (2006). Saúde é um direito ou um dever? Autocrítica da saúde pública. Revista Bioética, 2(2), 187-200.

Schramm, F. R. (2008). Bioética da Proteção: Ferramenta válida para enfrentar problemas morais na era da globalização. Revista Bioética, 16(1), 11-23.

Schramm, F. R. (2017). A bioética de proteção: Uma ferramenta para a avaliação das práticas sanitárias? Ciências \& Saúde Coletiva, 22(5), 1531-1538.

Segre, M., Silva, F. L., \& Schramm, F. R. (1998). O contexto histórico, semântico e filosófico do princípio de autonomia. Revista Bioética, 6(1), 1-9.

Sen, A. (2010). Desenvolvimento como liberdade. São Paulo: Companhia das Letras.

Recebido em: 10/08/2019

última revisão: 09/10/2019

Aceito em: 26/11/2019

\section{Sobre os autores:}

Paloma dos Santos Trabaquini: Mestre em Bioética pela Pontifícia Universidade Católica do Paraná (PUCPR). Docente das Faculdades do Vale do Juruena (AJES), Juína, Mato Grosso, Brasil. Enfermeira. E-mail: paloma.trabaquini@hotmail.com, Orcid: https://orcid.org/0000-0002-2641-4397

Caroline Filla Rosaneli: Pós-doutora pela Cátedra Unesco de Bioética da Universidade de Brasília (UnB). Docente do Programa de Pós-Graduação em Bioética da Pontifícia Universidade Católica do Paraná (PUCPR), Curitiba, Paraná, Brasil. Nutricionista. E-mail: caroline.rosaneli@gmail.com, Orcid: https://orcid.org/0000-0003-3710-5829

Thiago Rocha da Cunha: Pós-doutor pela Cátedra Unesco de Bioética da Universidade de Brasília (UnB). Docente do Programa de Pós-Graduação em Bioética da Pontifícia Universidade Católica do Paraná (PUCPR), Curitiba, Paraná, Brasil. Biomédico. E-mail: caixadothiago@gmail.com, Orcid: https://orcid.org/0000-0002-6330-2714

Cláudia Jaqueline Martinez Munhoz: Pós-doutora pela Universidade de Évora, Portugal. Docente da Universidade Federal de Mato Grosso (UFMT), Campus Sinop, Mato Grosso, Brasil. Enfermeira. E-mail: claudiajaquelinemartinezmunhoz@gmail.com, Orcid: https://orcid.org/0000-0003-4003-235X 